\title{
ANALISIS DAN PERANCANGAN INFRASTRUKTUR PRIVATE CLOUD DENGAN OPENSTACK
}

\author{
Muhammad Fauzan ${ }^{1}$, Andrew Fiade, Fenty Eka M. A. ${ }^{3}$ \\ ${ }^{\mathbf{1}}$ Mahasiswa Program Studi Teknik Informatika Fakultas Sains dan Teknologi \\ ${ }^{23}$ Staff Pengajar Program Studi Teknik Informatika Fakultas Sains dan Teknologi \\ Universitas Islam Negeri Syarif Hidayatullah Jakarta

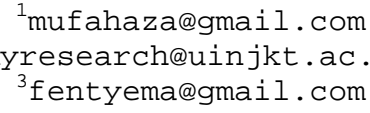

\begin{abstract}
Abstrak: Pusat TIK Nasional menggunakan infrastuktur IT konvensional dimana penggunaan resource masih bersifat boros, dan manajemen serta monitoring yang rumit. Oleh karena itu, perlu dirancang sebuah infrastruktur private cloud menggunakan Openstack yang dapat melakukan resource sharing. Tujuan perancangan privat cloud adalah melakukan efisiensi dan skalabilitas yang tinggi serta memudahkan akses, monitoring dan manajemen secara terpusat. Berdasarkan hasil penelitian yang dilakukan, sistem infrastruktur private cloud yang dirancang dan dibangun dengan Openstack versi Kilo menggunakan satu node controller dan satu node compute mampu melakukan efisiensi sumber daya infrastruktur IT sebesar 1 CPU dan 638.296 bytes RAM dan mampu melakukan resource sharing infrastruktur IT.
\end{abstract}

Kata Kunci: Cloud Computing, Private Cloud, Infrastructure as a Service, IaaS, Openstack

\begin{abstract}
The National ICT Center uses conventional IT infrastructure where resource use is still wasteful, and management and monitoring are complex. Therefore, it is necessary to construct a private cloud infrastructure by using Openstack that can do resource sharing. The purpose of private cloud design is to perform high efficiency and scalability and facilitate centralized access, monitoring and management. Based on the results of research conducted, using one node controller and one node compute efficiency and capacity can be done. CPU and 638,296 bytes of RAM and can do resource sharing of IT infrastructure.
\end{abstract}

Keywords: Cloud Computing, Private Cloud, Infrastructure As Service, IaaS, Openstack

\section{PENDAHULUAN}

Cloud computing adalah salah satu model komputasi yang belakangan ini banyak diterapkan, tidak hanya perusahaan yang bergerak di bidang teknologi, tapi perusahaan yang bergerak di bidang lain pun saat ini sudah banyak yang menggunakannya untuk menggerakkan perusahaannya. Penggunaan teknologi cloud computing pun tidak hanya mempermudah pekerjaan manusia, tetapi juga dapat mengurangi cost karena teknologi ini dapat menghemat resource yang tidak terpakai karena infrastruktur tidak dapat dibagi-bagi dan digunakan oleh pengguna lain, karena itulah infrastruktur cloud dikembangkan dan saat ini sudah memasuki masa pengembangan yang lebih jauh lagi. Untuk membangun infrastruktur cloud, diperlukan pemahaman yang jelas tentang kekuatan dan juga keterbatasan cloud computing oleh arsitek cloud tersebut, karena perbedaan kebutuhan infrastruktur yang dibangun akan juga akan membuat pengembangan dan pembangunan disetiap kasus berbeda-beda.

Pusat TIK Nasional adalah salah satu instansi pemerintahan di bawah pengawasan Kementerian Komunikasi dan Informatika yang berfokus pada pelatihan dan riset di bidang TIK. Menurut hasil 
Jurnal Pseudocode, Volume IV Nomor 2, September 2017, ISSN 2355-5920

www.ejournal.unib.ac.id/index.php/pseudocode

wawancara dengan staf IT Pusat TIK Nasional, diketahui bahwa pada infrastruktur IT di Pusat TIK Nasional, ketika kebutuhan sumber daya tidak mencukupi, staff IT harus secara menambahkan hardware secara manual. Selain itu, proses monitoring dan manajemen pun rumit, karena belum dapat dilakukan secara terpusat. Oleh karena itu, riset ini dilakukan untuk menyelesaikan masalah tersebut dengan membangun sebuah infrastruktur cloud di Pusat TIK Nasional.

Keuntungan dari private cloud dibanding public cloud (menyewa layanan cloud ke vendor), yaitu keamanan yang lebih tinggi karena cloud layanan ini hanya bergerak dalam jaringan internal Pusat TIK Nasional. Selain itu, Pusat TIK Nasional dapat menghemat bandwidth dan tidak perlu terus-menerus menyewa layanan cloud. Tetapi kebalikannya, pengembangan private cloud ini pun tidak lepas dari modal yang cukup besar, dibanding dengan menggunakan layanan public cloud, yang infrastrukturnya diurus oleh penyedia tersebut, private cloud membutuhkan departemen IT khusus untuk mengurus infrastrukturnya.

Untuk membangun sebuah infrastruktur cloud di Pusat TIK Nasional, dibutuhkan sebuah software atau platform, beberapa diantaranya yaitu Openstack, VMware VCloud, VMWare VSphere, Opennebula dan CloudStack. Untuk produk VMWare, dalam penggunaanya dikenakan biaya lisensi sementara produk opensource tidak dikenakan biaya dalam penggunaannya. Untuk menghemat pengeluaran Pihak IT Pusat TIK Nasional, dibangun infrastruktur cloud dengan software / platform Opensource.

Qiengye Jiang, dalam jurnal publikasinya [1] menjelaskan perbandingan platform cloud yang bersifat Opensource yang dikembangkan oleh komunitas dari tahin 2009 sampai dengan 2015 seperti yang dapat dilihat pada gambar 1.3.

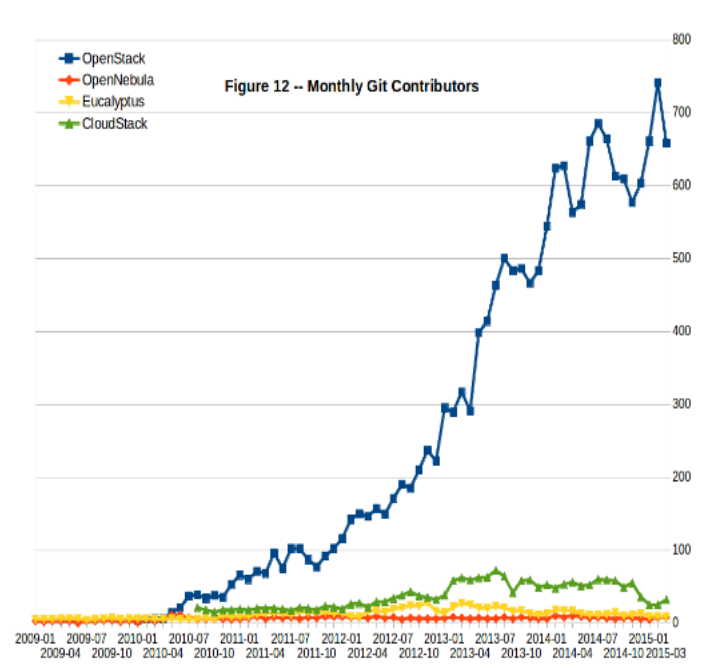

Gambar 1.1 Kontributor Git bulanan [1]

Pada gambar 1.1 dapat dilihat kontributor git pada platform Openstack jauh mengungguli platform komunitas lain. Statistik tersebut menunjukan bahwa, Openstack baru diciptakan pada tahun 2010, dimana jumlah kontributornya masih dibawah 100 orang, lalu. Dengan perkembangan yang pesat, pada tahun 2015 Openstack telah memiliki sebanyak 600 lebih contributor [2]. Pengertian Git itu sendiri adalah git adalah sebuah system versioning control (sistem kontrol versi) terdistribusi, atau biasa disebut dengan source code management software (aplikasi manajemen kode sumber), artinya soure code dan pengembangan Openstack disupport oleh banyak developer. perangkat lunak Openstack akan selalu berkembang cepat mengikuti kebutuhan yang ada.

Sementara itu, berdasarkan hasil survei dari OpenStack User Committee dibantu oleh Foundation staff dan independent data scientist yang melibatkan 1.325 users dan 352 deployment, Openstack digunakan perusahaan / organisasi berskala kecil, menengah, hingga yang berskala besar. 


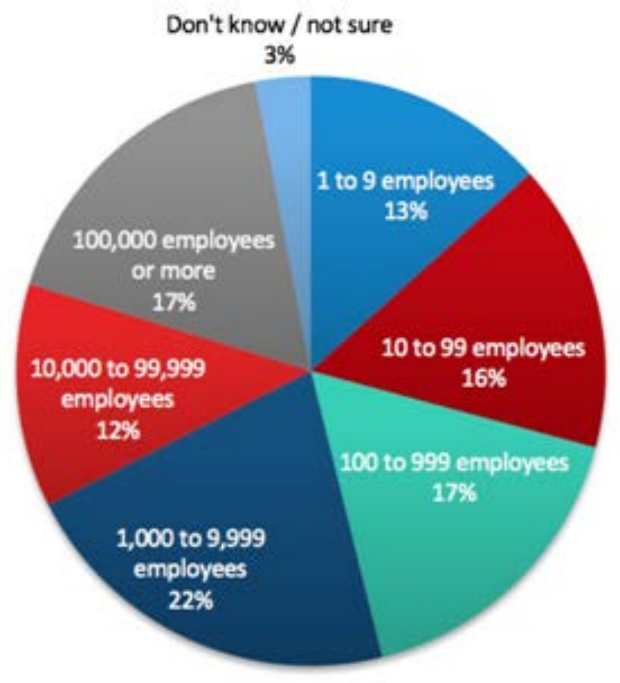

Gambar 1.2 Statistik organisasi / perusahaan pengguna Openstack berdasarkan skalanya [2]

Dari gambar 1.2 bisa dilihat bahwa pengguna Openstack terbanyak dengan raihan 22\% adalah organisasi / perusahaan yang memiliki 1.000 sampai 9.999 karyawan, lalu peringkat kedua dengan $17 \%$ suara adalah organisasi / perusahaan yang memiliki 100.000 karyawan lebih. Dari data ini dapat diketahui bahwa sudah banyak perusahaan / organisasi berskala besar yang mempercayakan departemen cloud-nya pada Openstack.

Berdasarkan data tersebut, masalah dapat dirumuskan sebagai berikut:

(a) Bagaimana merancang infrastruktur Private Cloud dengan Openstack yang mampu melakukan efisiensi sumber daya infrastruktur IT di Pusat TIK Nasional;

(b) Bagaimana merancang infrastruktur Private Cloud dengan Openstack yang mampu melakukan resource sharing IT di Pusat TIK Nasional.

Untuk menyelesaikan masalah diatas, dilakukan penelitian dengan tujuan sebagai berikut: (a) Merancang dan membangun infrastruktur private cloud dengan Openstack;

(b) Menguji fungsionalitas dan kapabilitas infrastruktur private cloud yang dibangun di Pusat TIK Nasional.

Penelitian yang dilakukan dibatasi pada:

(a) User harus terhubung dengan jaringan internal Pusat TIK Nasional untuk mengakses infrastruktur cloud;

(b) Infrastruktur cloud dibangun dengan arsitektur dua node, node controller untuk mengatur semua akses dan servis, dan node compute untuk melakukan komputasi dari servis-servis cloud, dan dengan satu network interface card pada masing-masing node;

(c) Tidak membahas sisi keamanan pada infrastruktur private cloud yang dibangun.

\section{LANDASAN TEORI}

\subsection{Cloud Computing}

Kemunculan

Cloud

Computing dilatarbelakangi oleh kebutuhan dunia industri dan komputerisasi akan pemanfaatan bersama sumber daya komputasi yang tersebar namun dapat digunakan sesuai keperluan (on demand). Hal lainnya yang mendukung munculnya teknologi Cloud Computing adalah teknologi web 2.0, teknologi Web Service, serta kemampuan komputasi otomatis yang dilakukan oleh komputer (automatic computation) terkait dengan manajemen sumber daya yang dimilikinya. Tentu saja, perkembangan perangkat keras (termasuk juga perangkat di jaringan komputer dan perangkat keras komputer), perangkat lunak (termasuk juga sistem operasi, aplikasi, metode pengembangan perangkat lunak, library), serta perkembangan internet (dengan kemunculan 4G dan 5G yang menandai kemajuan kecepatan internet di dunia), turut mendukung lahirnya Cloud Computing 
Jurnal Pseudocode, Volume IV Nomor 2, September 2017, ISSN 2355-5920

www.ejournal.unib.ac.id/index.php/pseudocode

sebagai sebuah teknologi dan layanan komputasi dan sumber daya komputasi [3].

Proses implementasi dari cloud computing membutuhkan pemahaman yang lebih baik. Pengetahuan tentang cloud computing dapat memberikan informasi yang lebih tentang definisi, arsitektur dan model-model delivery service yang dimilikinya. Isu dari cloud computing saat ini adalah efisiensi dan kelincahan dari sistem yang dimilikinya. Sistem ini juga secara sekaligus dapat meningkatkan kehandalan, keamanan dan pengendalian yang lebih baik, baik bagi pengguna maupun penyedia jasa. Pada setiap fase pengembangan desain dari cloud computing perlu dipertimbangkan penggunaan istilah-istilah yang benar, sehingga penggunanya dapat merasa nyaman dan tidak ragu-ragu dalam mengadopsi layanan-layanan yang akan dikirimkan kepada mereka oleh para penyedia jasa. Oleh karena itu, diperlukan cara yang efektif untuk mendistribusikan cloud computing kepada penggunanya [4].

\subsubsection{Layanan Cloud Computing (IaaS)}

Infrastructure as a Service adalah sebuah layanan yang menyewakan sumber daya teknologi informasi dasar, yang meliputi media penyimpanan, processing power, memory, sistem operasi, kapasitas jaringan, dan lain-lain yang dapat digunakan oleh pengguna untuk menjalankan aplikasi yang dimilikinya. IaaS memungkinkan perusahaan untuk memindahkan program yang ada kedalam cloud, dan menutup server lokal, dan data center.

Keuntungan dari IaaS ini adalah pengguna tidak perlu membeli komputer fisik dan konfigurasi komputer virtual tersebut sudah kelebihan beban, pengguna pun bisa menambahkan CPU, RAM dan storage dengan segera [5].

\subsubsection{Komponen Cloud Computing}

Di bawah ini akan dijelaskan pengertian dan fungsi dari Controller Node dan Compute node.

(a) Node Compute

Node Compute merupakan komponen pada Cloud Computing yang memiliki fungsi utama untuk melakukan kontrol terhadap node (komputer) pada sistem Cloud Computing.

(b) Node Controller

Node Controller merupakan komponen yang berhubungan langsung dengan pengguna layanan berbasis Cloud Computing. Para pengguna biasa maupun pengguna tertinggi (administrator). Sehingga posisi Cloud Controller tepat berada di antara pengguna layanan Cloud Computing dan Cluster Controller, yang tentu saja memiliki sejumlah Node Controller di belakangnya.

\subsection{Private Cloud}

Private cloud dimaksudkan sebagai model deployment Cloud Computing yang ditujukan untuk penggunaan yang terbatas pada kalangan tertentu saja (private), Model deployment ini umumnya banyak diterapkan untuk lingkungan laboratorium riset, sekolah, perpustakaan, gedung/bangunan (kantor/perusahaan), dan lainlain [3].

\subsection{Openstack}

Openstack adalah sebuah platform awan yang terdiri dari software open source untuk menyediakan basis menjalankan cloud IaaS (Infrastructure as a Service), baik pribadi maupun perusahaan yaitu berupa sumber daya untuk komputasi dan penyimpanan data dalam bentuk mesin virtual. Openstack mempunyai kemampuan skalabilitas yang lebih besar dibandingkan kerangka kerja awan lainnya [6].

Ada beberapa istilah yang sering digunakan oleh infrastruktur cloud berbasis Openstack, diantaranya yaitu: 
Jurnal Pseudocode, Volume IV Nomor 2, September 2017, ISSN 2355-5920

www.ejournal.unib.ac.id/index.php/pseudocode

(a) Tenant: Tenant adalah istilah yang digunakan Keystone dan equivalent dengan project dalam Horizon (web-ui). Tenant atau project adalah group items yang terdiri dari users, images, instances, networks, dan volume.

(b) Ephemeral Disk: Ephemeral Disk adalah sebuah temporary disk yang digunakan oleh instances (virtual machine).

(c) Instances: Instances adalah istilah di Openstack yang menandakan sebuah Virtual machines.

(d) Flavor: Flavor adalah hardware yang diasosiasikan ke instances (virtual machine) yang akan dibuat. Hardware tersebut adalah RAM, CPUs, dan Disks .

Openstack tersusun dari beberapa komponen. Adapun komponen-komponen tersebut adalah sebagai berikut:

1. Nova (Compute Service). Semua kegiatan yang diperlukan untuk mendukung siklus hidup dari instance dalam OpenStack cloud yang ditangani oleh Nova. Hal ini membuat Nova sebagai Platform Manajemen yang mengelola sumber daya komputasi, jaringan, otorisasi, dan kebutuhan skalabilitas dari OpenStack cloud.

2. Glance (Image Service) OpenStack Imaging Service adalah salah satu produk dari OpenStack yang digunakan untuk layanan virtual disk images.

3. Keystone (Identity Service) menyediakan layanan identitas dan akses kebijakan untuk semua komponen dalam keluarga OpenStack. Keystone menerapkan itu di REST-nya sendiri yang berbasis API (Identity API). Keystone menyediakan otentikasi dan otorisasi untuk semua komponen OpenStack. Otorisasi akan memverifikasi apakah pengguna yang terotentikasi memiliki akses ke layanannya yang dia minta atau tidak.

4. Neutron (Neutworking Service) adalah salah satu komponen openstack yang menyediakan layanan cloud Network as a Service. Neutron menyediakan API yang memungkinkan Anda menentukan konektivitas jaringan dan menangani di awan.

5. Cinder (Block Storage Service) adalah komponen penyimpanan blok yang lebih analog dengan gagasan tradisional komputer yang dapat mengakses lokasi tertentu pada disk drive serta menyediakan perangkat penyimpanan untuk digunakan dengan instances pada OpenStack.

6. Horizon (User Interface Service) merupakan suatu layanan user interface dalam infrastruktur Openstack yang memberikan akses visusalisasi bagi user dalam menciptakan cloud.

\section{METODE PENELITIAN}

Dengan metode pengembangan sistem NDLC, dilakukan enam tahapan dasar dalam membangun/mengembangkan sistem.

(a) Analisis. Melakukan identifikasi dan menemukan permasalahan yang ada, dipahami mengapa permasalahan itu terjadi di Pusat TIK Nasional, dan hal apa saja yang ditimbulkan dari permasalahan itu.

(b) Design. Pada tahap ini, diperbaiki sistem berjalan atau dirancang sistem baru. Pada riset ini ditambahkan sebuah infrastruktur cloud diterapkan di lokasi penelitian.

(c) Simulasi Prototipe. Sebelum mengimplementasikan pada sistem berjalan, dilakukan riset dan percobaan terlebih dahulu agar diketahui masalah apa yang akan dihadapi pada saat implementasi. 
Jurnal Pseudocode, Volume IV Nomor 2, September 2017, ISSN 2355-5920 www.ejournal.unib.ac.id/index.php/pseudocode

(d) Implementasi. Berbekal hasil riset dan percobaan simulasi, dilakukan implementasi infrastruktur cloud yang sudah di design sebelumnya.

(e) Monitoring. Setelah berhasil mengimplementasikan sistem infrastruktur cloud, sistem baru akan diuji apa berjalan semestinya atau tidak.

(f) Manajemen. Agar sistem infrastrutur cloud yang dibangun dapat digunakan dengan baik dan bertahan lama, perlu dilakukan aktivitas perawatan, pemeliharaan, serta pengololaah dari sistem yang telah dibangun. Tahapan ini juga menentukan siapa saja yang dapat mengakses dan mengelola sistem infrastruktur cloud.

\section{PERANCANGAN SISTEM}

\subsection{Analisis}

Tabel 4.1Kebutuhan Hardware

\begin{tabular}{|c|c|c|}
\hline NO & HARDWARE & KETERANGAN \\
\hline 1 & Server 2 pcs & $\begin{array}{l}\text { Sebagai penyedia } \\
\text { resource cloud }\end{array}$ \\
\hline 2 & NIC $2 p c s$ & $\begin{array}{l}\text { Sebagai } \\
\text { penghubung ke } \\
\text { jaringan intranet } \\
\text { Pustiknas, masing- } \\
\text { masing node } \\
\text { menggunakan satu } \\
\text { buah NIC }\end{array}$ \\
\hline 3 & Laptop & Sebagai client \\
\hline
\end{tabular}

Kebutuhan software:

1. Ubuntu Server 14.04. Sebagai sistem operasi untuk server. Dipilih versi 14.04 dibanding versi 15.10 (terbaru) karena versi ini adalah versi Long Time Support (LTS)

2. Open SSH Server. Digunakan untuk melakukan remote dari client ke cloud node
3. Git. Digunakan untuk mengambil source code Openstack terbaru langsung dari Github

4. Openstack. Versi yang digunakan adalah versi “Kilo” dimana versi ini sudah stabil dan sudah banyak digunakan.

5. NTP. NTP akan di-install di controller node dan compute node agar waktu dapat tersingkronisasi.

6. MySQL. Dipilih database ini karena dukungan dari komunitas yang tinggi Selain itu, diketahui bagaimana menggunakannya dan command-command MySQL.

7. Python-mysqldb. dibutuhkan package ini karena sebagian besar source code openstack tertulis dengan phython database yang digunakan adalah MySQL.

8. RabbitMQ. Sebagai protokol untuk saling berkirim pesan antar node dalam infrasturtukr cloud.

9. Qemu. Sebagai tools untuk menjalankan virtualisasi. Dipilih Qemu dibanding KVM karena KVM membutuhkan teknologi hardware assisted dari Intel-VT / AMD-VT dimana spesifikasi server yang digunakan belum memiliki fitur ini, sementara Qemu tidak membutuhkan teknologi hardware assisted.

10. LVM. Sebagai protokol block storage driver. 


\subsection{Design}

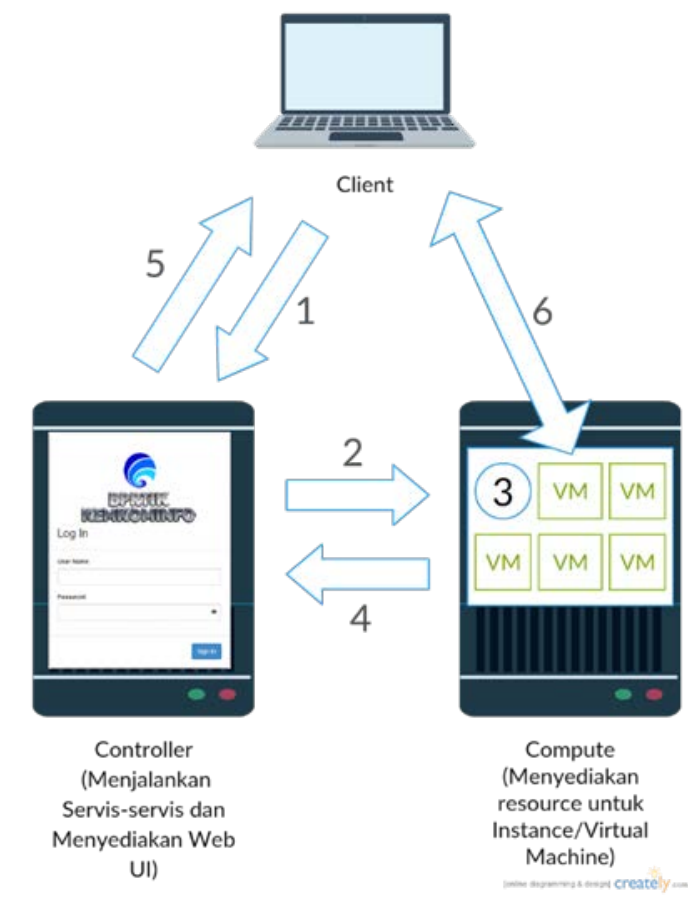

Gambar 4.1 Alur pembuatan Instance / Virtual Machine

Seperti yang dapat dilihat pada gambar 4.3, sistem dapat dijelaskan dengan alur sebagai berikut:

1. User / client melakukan login kepada web UI yang tersedia di node controller, setelah berhasil login, user dapat melakukan perintah pembuatan Instance pada web UI tersebut.

2. Setelah itu, service Openstack di controller node akan melakukan request pembuatan Instance pada compute node.

3. Node compute akan melakukan pembuatan instance / VM.

4. Setelah berhasil, node compute akan mengirimkan endpoint pada node controller sebagai identitas dari instance / VM yang dibuat.

5. Setelah itu, instance / VM yang dibuat akan menunjukan status active pada web UI Openstack.

6. User / client pun dapat mengakses instance / $\mathrm{VM}$ via SSH / VNC.

\subsection{Simulasi Prototipe}

Dengan membuat simulation prototype pada software Oracle VM Virtualbox, dapat dibuat snapshot (system restore) sehingga ketika terjadi masalah, hanya perlu di-restore snapshot yang ada, tanpa perlu mengulang dari awal.

\subsection{Implementasi}

Pada tahap ini dilakukan beberapa konfigurasi berikut ini;

(a) Pada controller node dilakukan konfigurasi pada file keystone.conf, glance-api.conf, glance-registry.conf, nova.conf, neutron.conf, $\quad$ cinder.conf dan local_setting.py.

(b) Pada compute node dilakukan konfigurasi pada file nova.conf dan neutron.conf.

Setelah melakukan konfigurasi tersebut, hal selanjutnya yang dilakukan adalah Melakukan singkronisasi database komponen-komponen Openstack. Lalu merestart service-service Openstack.

\section{HASIL DAN PEMBAHASAN}

Setelah fase implementasi berhasil dilakukan, tahap selanjutnya yang dilakukan adalah melakukan monitoring. Pada tahap monitoring, dilakukan pengecekan terhadap implementasi yang telah dilakukan. Beberapa hal yang dilakukan adalah sebagai berikut:

(a) Membuat flavor. Setelah login berhasil. Pilih menu Admin -> Sistem lalu pilih menu “Flavor”, lalu pilih “Create Flavor”. 
Jurnal Pseudocode, Volume IV Nomor 2, September 2017, ISSN 2355-5920

www.ejournal.unib.ac.id/index.php/pseudocode

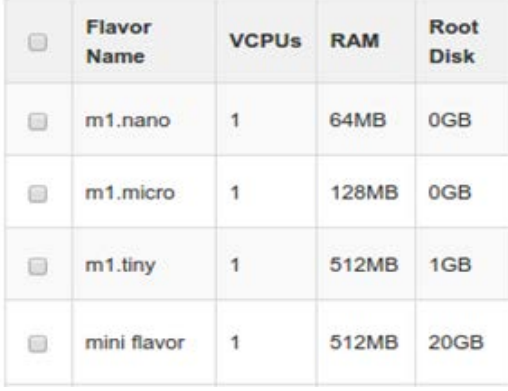

Gambar 5.1 Flavor Berhasil Dibuat

(b) Membuat keypair. Untuk membuat keypair, masuk menu project -> compute -> access \& security, pilih tab "Key Pairs" lalu klik tombol “Create Key Pair”. Lalu akan muncul sebuah pop up untuk mengisi nama keypair yang akan dibuat. Setelah memberi nama keypair, klik “Create Key Pair” yang ada pada pop up tersebut.

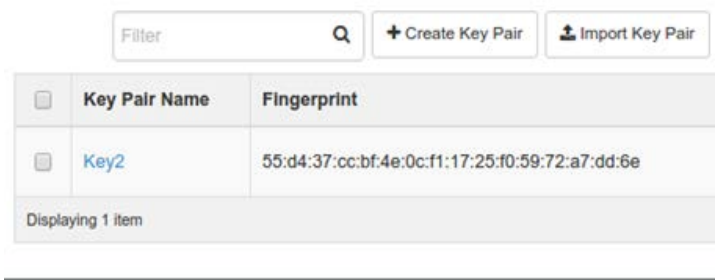

Gambar 5.2 Keypair Berhasil Dibuat

(c) Menambah image. Untuk menambah sebuah image pada sistem infrastruktur cloud openstack, pilih menu project -> compute -> image, klik tombol “create image”.

\begin{tabular}{|l|l|l|l|}
\hline$\square$ & Image Name & Type & Status \\
\hline$\square$ & Deblan Cloud & Image & Active \\
\hline$\square$ & cirros-0.3.4-x86_64-uec & Image & Active \\
\hline$\square$ & cirros-0.3.4-x86_64-uec-ramdisk & Image & Active \\
\hline
\end{tabular}

Gambar 5.3 Image Berhasil Ditambah

(d) Membangun dan Mengakses Instance. Untuk membangun sebuah instance, pilih menu project -> compute -> instances, lalu klik tombol "Launch Instance" dan akan muncul sebuah pop up pembuatan instance. Setelah muncul pop up tersebut, isi kolom-kolom yang ada dengan pada tab details tersebut. Setelah tab details sudah terisi semua, pindahkan tab aktif pada tab “access \& security” lalu pilih keypair yang sebelumnya telah dibuat. Setelah itu, klik tombol “Launch” agar pembuatan instance dimulai.

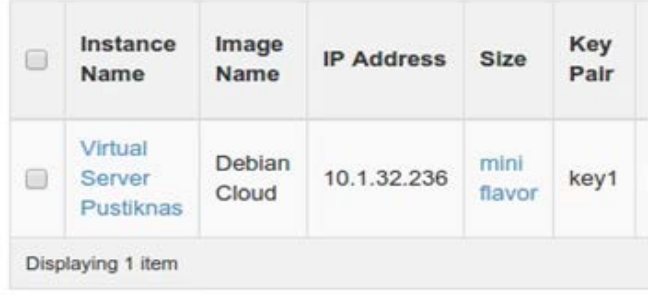

Gambar 5.4 Instance Berhasil Dibangun

Setelah Instance berstatus running, instances dapat diakses melalui SSH dengan menggunakan keypair yang dipilih sebelummnya.

\section{$=$ debian@virtual-server-pustiknas: \\ fef $\sim$ \$sh $-i$ Downloads/key1.pem debian@10.1.32.236}

The programs included with the Debian GNU/Linux system a the exact distribution terms for each program are descri individual files in /usr/share/doc/*/copyright.

Debian GNU/Linux comes with ABSOLUTELY NO WARRANTY, to $t$ permitted by applicable law.

debian@virtual-server-pustiknas: \$

\section{Gambar 5.5 Mengakses Instance via SSH}

Setelah fase monitoring, fase yang selanjutnya dilakukan adalah fase manajemen. Berikut ini adalah beberapa aktivitas yang akan dilakukan dalam fase ini:

(a) Manajemen User. Untuk memiliki sistem yang aman, user biasa diberi role user untuk membatasi akses terhadap sistem. Sebalikanya, seorang admin membutuhkan role administrator untuk mengurus dan memelihara sistem infrastruktur cloud yang telah dibuat sehingga administrator dapat melihat keseluruhan user yang ada.

(b) Manajemen Resource. Uuntuk mengawasi penggunaan resource, seorang administrator 
Jurnal Pseudocode, Volume IV Nomor 2, September 2017, ISSN 2355-5920 www.ejournal.unib.ac.id/index.php/pseudocode

harus seringkali melihat resource usage yang digunakan.

(c) Manajemen System. Sebuah sistem yang baru diterapkan biasanya memiliki masalahmasalah yang baru terlihat pada saat menggunakannya. Oleh karena itu, dibutuhkan aturan dan langkah-langkah yang harus dilakukan agar user tidak terganggu dengan masalah yang ada. Adapun aturan dan langkah-langkah tersebut adalah sebagai berkut:

1. User yang menemui masalah pada sistem melaporkan pada administrator mengenai masalah yang dirasakannya.

2. Admin yang menemui masalah atau mendapat laporan dari user mengenai masalah memperbaiki sistem secepat mungkin.

3. Administrator mengikuti perkembangan sistem dan versi Openstack terbaru yang dirilis setiap enam bulan sekali, dan melakukan update dalam jangka waktu agar dapat terus mendapat support pada sistem openstack yang digunakan.

Berikut ini adalah spesifikasi dan penggunaan resource RAM dan CPU pada server Pusat TIK Nasional di ruang $\mathrm{RnD} 2$ (Research and Development).

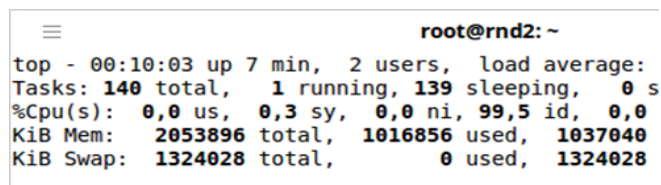

Gambar 5.6 Penggunaan RAM server RnD 2 tanpa cloud

\begin{tabular}{ll}
\hline$\equiv$ & \multicolumn{1}{c}{$\quad$ root@rnd2: } \\
root@rnd2: \# lscpu & \\
Architecture: & x86 64 \\
CPU op-mode(s): & 32 -bit, 64-bit \\
Byte Order: & Little Endian \\
CPU(s): & 2 \\
On-line CPU(s) list: & 0,1 \\
Thread(s) per core: & 1 \\
Core $(s)$ per socket: & 2 \\
Socket(s): & 1 \\
NUMA node $(s):$ & 1 \\
Vendor ID: & GenuineIntel
\end{tabular}

Gambar 5.7 Spesifikasi CPU server RnD 2 tanpa cloud

Berikut ini adalah tampilan spesifikasi instance setelah dibangun dengan menjalankan perintah “lscpu”.

\begin{tabular}{|c|c|c|c|}
\hline debian@virt & lal-server-pustiknas: & - & $\square$ \\
\hline \multicolumn{4}{|c|}{ debian@virtual-server-pustiknas: $\$$ lscpu } \\
\hline Architecture: & $x 86 \_64$ & & \\
\hline CPU op-mode(s): & 32-bit, $64-$ bit & & \\
\hline Byte order: & Little Endian & & \\
\hline CPU(s): & 1 & & \\
\hline On-line CPU(s) list: & $\theta$ & & \\
\hline Thread(s) per core: & 1 & & \\
\hline Core(s) per socket: & 1 & & \\
\hline Socket(s): & 1 & & \\
\hline NUMA node (s): & 1 & & \\
\hline Vendor ID: & AuthenticAMD & & \\
\hline
\end{tabular}

Gambar 5.8 Spesifikasi yang digunakan oleh instance

Lalu penggunaan dan spesifikasi RAM pada instance dapat dilihat pada gambar dibawah ini.

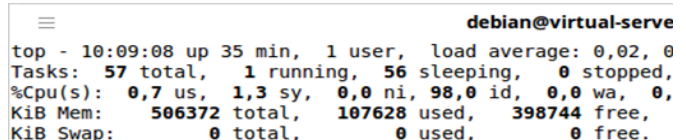

Gambar 5.9 Spesifikasi RAM yang digunakan oleh Instance

Seperti yang dapat dilihat pada gambar 5.19, RAM dengan infrastruktur cloud yang tidak digunakan sebesar 398.744 bytes. Sementara itu penggunaan RAM tanpa infrastruktur cloud adalah sebesar 1.037 .040 bytes.

Dari pengujian diatas dapat diketahui bahwa infrastruktur IT yang dibangun dengan Openstack di Pusat TIK Nasional mampu melakukan efisiensi resource sebesar 1 buah CPU dan RAM sebesar 638.296 bytes. 
Jurnal Pseudocode, Volume IV Nomor 2, September 2017, ISSN 2355-5920 www.ejournal.unib.ac.id/index.php/pseudocode

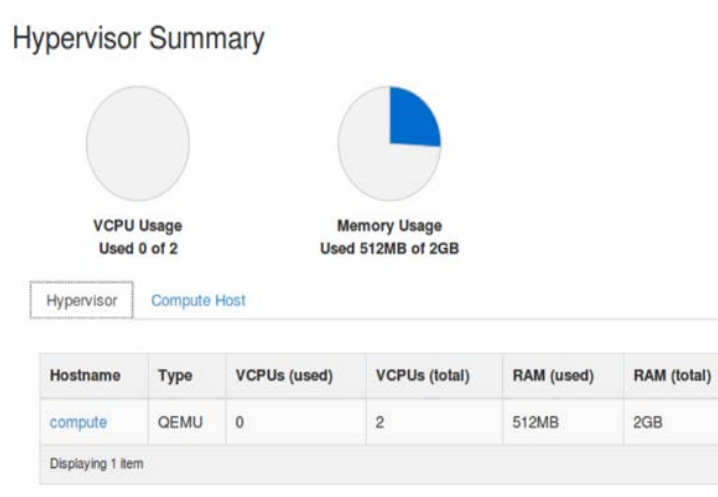

Gambar 5.10 Resource yang di-sharing oleh compute node

Dari gambar 5.11, dapat dilihat bahwa hostname compute node yang menggunakan hypervisor qemu berhasil melakukan sharing resource sebesar 2 VCPU (Virtualized CPU) dan 2 GB memory yang merupakan spesifikasi dari server compute node.

\section{PENUTUP}

\subsection{Kesimpulan}

Berdasarkan hasil analisa, perancangan dan implementasi yang telah dilakukan, dapat disimpulkan bahwa:

1. Infrastruktur Private Cloud yang dirancang dengan Openstack di Pusat TIK Nasional mampu melakukan efisiensi sumber daya infrastruktur IT sebesar 1 CPU dan 638.296 bytes RAM.

2. Node compute pada Infrastruktur Private Cloud yang dirancang dengan Openstack di
Pusat TIK Nasional mampu melakukan sharing resource infrastruktur IT.

\subsection{Saran}

Sebagai pengembangan dari penelitian yang telah dilakukan sebelumnya, diberikan saran sebagai berikut:

1. Karena pada penelitian kali ini digunakan spesifikasi komputer desktop / personal computer (PC). Untuk pengembangan selanjutnya, sistem diharapkan dibangun menggunakan komputer dengan spesifikasi server, dengan itu performance dari sistem infrastruktur cloud computing dapat berjalan lebih baik lagi.

2. Untuk pengembangan selanjutnya diharapkan untuk menambah node compute agar tercipta skalabilitas yang lebih besar lagi.

\section{REFERENSI}

[1] Jiang, Q. (2013). CY13-Q3 Community Analysis OpenStack vs OpenNebula vs Eucalyptus vs CloudStack. University of Sydney. Sumber: http://www.qyjohn.net/?p=3373

[2] OpenStack. (2015). OPENSTACK USER SURVEY : A snapshot of OpenStack users , attitudes and deployments. Openstack.org.

[3] Pratama, I. P. A. E. (2014). Smart City beserta Cloud Computing dan Teknologi-teknologi Pendukung Lainnya. Bandung: Penerbit Informatika Bandung.

[4] Afdhal. (2013). Studi Perbandingan Layanan Cloud Computing. Rekayasa Elektrika.

[5] Budiyanto, A. (2012). Pengantar Cloud Computing. Cloud Indonesia, Jakarta.

[6] Fetria, D. F., Wibowo, T. A., Purnomo, J., Elektro, F. T., Telkom, U., \& Engineering, S. (2015). Implementasi dan Analisis Platform Horizon Dalam Service Dashboard Berbasis Openstack. Universitas Telkom. 